\title{
Influence of substituent and ligand electronic factors on the measurement of gas phase olefins using a surface acoustic wave oscillator coated with trans $-\mathrm{PtCl}_{2}($ olefin) (amine) complexes
}

\author{
Edward T. Zellers and Guo-Zheng Zhang \\ Department of Environmental and Industrial Health, School of Public Health, University of Michigan, \\ Ann Arbor, MI 48109-2029 (USA)
}

(Received 29th January 1993)

\begin{abstract}
Certain olefin gases and vapors can be measured selectively at low concentrations using surface acoustic wave (SAW) sensors çated with reagents of the general formula trans- $\mathrm{PtCl}_{2}$ (olefin)(amine). The sensor response depends on the steady-state rate of mass change associated with substitution of the initially complexed olefin by the free olefin analyte. This paper examines the effects of changes in the electronic nature of substituents on the free olefin and the olefin and amine ligands in the complex on the sensitivity and selectivity obtained with this class of SAW sensor coatings. For a given reagent, higher reaction rates are generally observed with electron-donating substituents on the double bond of the free olefin. For a given free olefin, varying the 4-substituent of the pyridine ligand in $\mathrm{PtCl}_{2}$ (ethylene)(4-X-pyridine) gives a maximum response at an intermediate degree of amine basicity. Replacing pyridine by aniline, pyridine $N$-oxide or the 4-substituted derivatives of these ligands results in reduced responses for the olefins tested. Changing the initially complexed olefin leads to large changes in response, the pattern of which varies with the nature of the free olefin. Results demonstrate the potential for controlling the response of SAW sensors through subtle structural modifications of these coating reagents.
\end{abstract}

Keywords: Acoustic methods; Gas sensor; Olefin; Surface acoustic wave sensor; Transition metal complex

Olefins comprise an industrially important class of organic compounds used primarily in the production of polymers. Adverse health effects ranging from mild respiratory tract irritation to cancer and birth defects have been associated with exposure to different olefins in humans and test animals [1]. As a result, regulatory exposure limits have been established to minimize the risk of injury and disease in production workers and the general population [2,3]. Ensuring compliance

Correspondence to: E.T. Zellers, Department of Environmental and Industrial Health, School of Public Health, University of Michigan, Ann Arbor, MI 48109-2029 (USA). with such standards requires accurate monitoring of these compounds in the atmosphere, often in the presence of other air contaminants. Unfortunately, portable instruments suitable for routine monitoring of personnel exposures to olefin gases and vapors are limited by a lack of sensitivity and/or selectivity [4].

Surface acoustic wave (SAW) sensors and sensor arrays have the potential to address these shortcomings by providing selective measurement of a broad range of organic gases and vapors $[5,6]$. In the SAW sensor, a high-frequency mechanical wave is generated along the surface of a piezoelectric substrate which has been coated with 
a chemically sensitive film. The most common configuration used for sensing applications employs the SAW device as the frequency controlling element in an oscillator circuit. A feedback amplifier is incorporated between the input and output transducers of the device, resulting in oscillation at a fixed frequency, $f_{0}$. Small changes in the physical properties (e.g., mass) of the coating film result in a change of the velocity of the propagating wave, and hence of the oscillator frequency [6].

The following approximate expression can be used to relate the change of the SAW oscillator frequency to changes of deposited mass at the surface of the sensor [7]:

$$
\Delta f=K_{\mathrm{s}} f_{0}^{2} \Delta m / a
$$

where $\Delta f$ is the change of frequency $(\mathrm{Hz}), K_{\mathrm{s}}$ is a negative substrate-dependent constant $\left(\mathrm{m}^{2} \mathrm{~s}\right.$ $\left.\mathrm{kg}^{-1}\right), f_{0}$ is the oscillation frequency of the uncoated device $(\mathrm{Hz})$, and $\Delta m / a$ is the change of coating mass per unit area $\left(\mathrm{kg} \mathrm{m}^{-2}\right)$. This relationship allows one to estimate both the amount of coating deposited on the sensor and the changes in the coating mass resulting from subsequent interactions with gas phase analytes.

In attempting to design sensor coatings that will respond to olefins, advantage can be taken of the ability for the $\mathrm{C}=\mathrm{C}$ functional group to coordinate, often reversibly, to various transition metal compounds [8,9]. In this way selectivity for olefins in the presence of non-coordinating non-olefin organic vapors would be expected. The more difficult problem is to obtain selectivity for a given olefin in the presence of other olefins.

In a series of recent papers we have shown that a number of olefins can be measured selectivity in the presence of industrially relevant non-olefin organic solvent vapors and structurally similar olefin gases and vapors using SAW oscillators coated with the reagent complex trans$\mathrm{PtCl}_{2}$ (ethylene)(pyridine) and related complexes [10-13]. The reaction is shown below in general form:

$$
\begin{gathered}
\text { trans }-\mathrm{PtCl}_{2}\left(\mathrm{OL}_{1}\right)(\mathrm{AM})+\mathrm{OL}_{2} \rightleftarrows \\
\text { trans }-\mathrm{PtCl}_{2}\left(\mathrm{OL}_{2}\right)(\mathrm{AM})+\mathrm{OL}_{1}
\end{gathered}
$$

where $\mathrm{OL}_{1}$ and $\mathrm{OL}_{2}$ represent the initially complexed and free olefins, respectively, and $A M$ is the trans-amine ligand. A useful property of this class of reagents is the capability for regeneration following exposure to the target olefin by brief exposure to the initially complexed olefin which drives the olefin-exchange reaction in the reverse direction.

Results from our earlier studies suggested that the selectivity observed for the target olefins in the presence of other olefins could be attributed to electronic and steric factors [11,12]. The importance of steric factors was investigated in a subsequent study where it was shown that bulky substituents on the gas phase olefin or on the pyridine ligand (i.e., in the 2 or 6 positions on the pyridine ring) dramatically reduced the rate of the substitution reaction and permitted the measurcment of less sterically hindered olefins in the presence of their more sterically hindered isomers and structural analogues [13]. The influence of the electronic structural features of the free olefins and the ligands in the $\mathrm{Pt}$-olefin complex has not yet been systematically explored.

The coating reagents investigated here are examples of square-planar metal-olefin $\pi$-complexes which have amine and olefin ligands in a trans configuration about a central $\mathrm{Pt}(\mathrm{II})$ atom $[8,14]$. The olefin is bound to $\mathrm{Pt}$ via a $\sigma$ bond, involving donation of electron density from the olefin $\pi$ cloud to the Pt, as well as by a $\pi$ bond, involving back-bonding from the metal to the antibonding orbitals of the olefin. The relative importance of each of these bonding interactions depends on the overlaps and energies of the respective orbitals on the metal and the olefin, though it is generally accepted that the $\sigma$ bond is predominant [15].

Both the rates and mechanisms of olefin-substitution reactions in these complexes are affected by the amine ligand [16,17]. The $\sigma$-bond strength of the amine is determined primarily by its basicity. In addition, where the amine has low-lying vacant $p$ orbitals, as in pyridine and pyridine $N$-oxide, back-bonding from the metal is possible. This interaction does not occur with aniline due to the unavailability of accepting orbitals. The competitive donation (via $\sigma$ bonding) 
and acceptance (via $\pi$ bonding) of electron density between between the amine and olefin can thus affect the overall reactivity of the complex. When a free olefin reacts it replaces the initially bound olefin without disrupting the spatial configuration of the other ligands. Where the amine is pyridine or pyridine $\mathrm{N}$-oxide the reaction proceeds exclusively through a pentacoordinate associative transition state [16]. Where the amine is aniline both solvent-assisted and associative pathways are observed [17].

In the study described here, we examine the effect of substituents on the free olefin and the amine and olefin ligands in the complex on the relative reactivities of the complexes and the extent to which such effects might be used to adjust the sensitivity and selectivity of a SAW sensor having these complexes as coatings. Coating reagents examined include $\mathrm{PtCl}_{2}$ (ethylene)(AM) (AM $=$ pyridine, aniline, pyridine $N$-oxide and their 4-substituted derivatives) and $\mathrm{PtCl}_{2}\left(\mathrm{OL}_{1}\right)$ (pyridine) $\left(\mathrm{OL}_{1}=1\right.$-butene, 1-hexene and 1-octene).

The sensor response at steady-state is a function of the change of mass accompanying the olefin substitution and it will therefore depend on the gas phase olefin concentration. Furthermore, since there is a $1: 1$ stoichiometry between reactants and products, the rate of frequency change of the sensor $\mathrm{d} f / \mathrm{d} t$, will depend on the steadystate reaction rate according to the following equation [11]:

$\mathrm{d} f / \mathrm{d} t=-C\left(\mathrm{MW}_{2}-\mathrm{MW}_{1}\right) \mathrm{d} N / \mathrm{d} t$

where $M W_{i}$ is the molecular weight of the free or initially complexed olefin, $N$ is the number of moles of each olefin involved in the reaction and $C$ is a constant. Thus, for equivalent reaction rates, the greater the MW difference between the attacking and leaving olefin, the greater will be the sensor response.

TABLE 1

Analytical data for the trans- $\mathrm{PtCl}_{2}\left(\mathrm{OL}_{1}\right)(\mathrm{AM})$ reagents

\begin{tabular}{|c|c|c|c|c|c|c|c|}
\hline \multirow{2}{*}{$\begin{array}{l}\text { Complex } \\
\mathrm{X}\end{array}$} & \multirow{2}{*}{$\begin{array}{l}\text { m.p. } \\
\left({ }^{\circ} \mathrm{C}\right)\end{array}$} & \multicolumn{3}{|l|}{ Calc. } & \multicolumn{3}{|l|}{ Found } \\
\hline & & $\% \mathrm{C}$ & $\% \mathrm{H}$ & $\% \mathbf{N}$ & $\% \mathrm{C}$ & $\% \mathbf{H}$ & $\% \mathbf{N}$ \\
\hline \multicolumn{8}{|c|}{$O L_{1}=$ ethylene, $A M=4-X$-pyridine,$X=$} \\
\hline$-\mathrm{N}\left(\mathrm{CH}_{3}\right)_{2}$ & 124 & 25.97 & 3.39 & 6.73 & 26.01 & 3.44 & 6.68 \\
\hline$-\mathrm{OH}$ & 122 & 21.61 & 2.33 & 3.60 & 21.64 & 2.35 & 3.57 \\
\hline$-\mathrm{CH}_{3}$ & 117 & 24.82 & 2.86 & 3.62 & 24.90 & 2.90 & 3.60 \\
\hline$-\mathrm{H}$ & 112 & 22.53 & 2.43 & 3.75 & 22.50 & 2.50 & 3.70 \\
\hline$-\mathrm{Cl}$ & 120 & 20.63 & 1.98 & 3.44 & 20.80 & 2.00 & 3.40 \\
\hline$-\mathrm{CN}$ & 145 & 24.13 & 2.03 & 7.04 & 24.01 & 1.92 & 6.98 \\
\hline \multicolumn{8}{|c|}{$O L_{1}=$ ethylene, $A M=4-X$-aniline, $X=$} \\
\hline$-\mathrm{H}$ & 110 & 24.81 & 2.86 & 3.62 & 24.83 & 2.84 & 3.30 \\
\hline$-\mathrm{CH}_{3}$ & 114 & 26.94 & 3.27 & 3.49 & 26.82 & 3.26 & 3.67 \\
\hline$-\mathrm{Cl}$ & 116 & 22.79 & 2.39 & 3.32 & 22.64 & 2.39 & 3.23 \\
\hline \multicolumn{8}{|c|}{$O L_{1}=$ ethylene, $A M=4-X$-pyridine $N$-oxide, $X=$} \\
\hline$-\mathbf{H}$ & 146 & 21.61 & 2.33 & - & 21.67 & 2.33 & - \\
\hline$-\mathrm{CH}_{3}$ & 147 & 23.83 & 2.75 & - & 24.29 & 2.82 & - \\
\hline$-\mathrm{Cl}$ & 165 & 19.85 & 1.90 & - & 19.77 & 1.82 & - \\
\hline \multicolumn{8}{|c|}{$A M=$ pyridine,$O L_{l}=$} \\
\hline Ethylene & 112 & 22.53 & 2.43 & 3.75 & 22.50 & 2.50 & 3.70 \\
\hline 1-Butene & 106 & 26.94 & 3.27 & - & 26.77 & 3.33 & - \\
\hline 1-Hexene & 40 & 30.77 & 3.99 & - & 30.58 & 3.99 & - \\
\hline 1-Octene & - & 34.14 & 4.63 & - & 34.15 & 4.77 & - \\
\hline
\end{tabular}




\section{EXPERIMENTAL}

Most of the starting materials, solvents and gases were obtained from Aldrich (Milwaukee, WI) and were used without further purification, with the exception of pyridine $N$-oxide which was purified by fractional distillation. Ethylene, vinyl chloride and vinyl bromide gases were obtained from Matheson Gas Products (Secaucus, NJ). Elemental analyses were performed by Galbraith (Knoxville, TN). Particle size distributions were determined according to established methods [18] using an Olympus Model BHA optical microscope.

trans- $\mathrm{PtCl}_{2}$ (ethylene)(amine) reagents were synthesized by the addition of 1 molar equivalent of the amine to a stirred aqueous solution of $\mathrm{KPtCl}_{3}$ (ethylene) (Zeise's salt) at room temperature [14]. The crude solid precipitates were recrystallized after air drying from a minimum of dichloromethane by adding an excess of hexane or petroleum ether. All of the products were isolated as yellow crystalline solids.

Conversion of the ethylene complexes to the corresponding olefin-substituted reagents was performed by combining the ethylene complex with an excess of the olefin in dichloromethane and refluxing for 1-2 h. These products were isolated and recrystallized as described above. In the case of $\mathrm{PtCl}_{2}$ (1-hexene)(pyridine) and $\mathrm{PtCl}_{2}$ (1-octene)(pyridine), the products were difficult to recrystallize and were generally isolated as viscous oils. The former complex could be obtained as a low-melting solid upon repeated recrystallizations. The complexes investigated are listed in Table 1 along with the corresponding melting points and elemental analyses.

Combining the $\mathrm{Pt}$-olefin complexes with the amorphous rubbery polymer, poly(isobutylene) (PIB, Scientific Polymer Products, Ontario, NY) improved the coating uniformity and response reproducibility relative to the use of the solid complexes alone. Films were deposited on the entire active area of the sensor either by solvent casting or spray-coating from solutions containing approximately $6 \mathrm{mg} \mathrm{ml}^{-1}$ of each component in toluene: hexane $(2: 1)$. The mass deposited was estimated from the net frequency shift via Eqn. 1 after evaporation of the casting solvent. For all experiments described here, the frequency shift due to the coating film was in the range of $200-400 \mathrm{kHz}$, corresponding to deposited masses of $260-520 \mu \mathrm{g}$.

It has been shown that the reference device can be coated with an equivalent amount of PIB so that measuring the difference frequency would cancel the transient responses due to physical sorption and desorption of vapors by the polymer component of the reagent-coated sensor $[10,12]$. Therefore measurements collected for this study were made using a single oscillator and the response was determined after allowing a short time for equilibration: this typically required 30 $90 \mathrm{~s}$ owing to mixing in the chamber and to establishment of steady-state reaction conditions within the sensor coating.

A 30-MHz ST-quartz SAW oscillator with $\mathrm{Au}$ on-Cr metallization and an active area of $1.5 \mathrm{~cm}^{2}$ was used for all tests [11]. Series inductors were used as tuning elements and two LM733 amplifiers provided the gain necessary to maintain oscillations in the SAW device. The sensor frequency was monitored with a digital frequency counter (Hewlett-Packard 5384A) and monitored with a personal computer via an IEEE-488 interface. Signals were collected every $10 \mathrm{~s}$ at a resolution of $1 \mathrm{~Hz}$ and the net 1-min frequency shifts were averaged over the exposure interval at a given olefin concentration to yield the rate of frequency change in $\mathrm{Hz} \mathrm{min}^{-1}$.

The sensor was placed in a stainless-steel chamber equipped with gas inlet and outlet ports. Electrical connections were made using coaxial cables and connectors in the bottom of the chamber. The chamber was wrapped with heating tape to control the temperature and a thermocouple was used to monitor the temperature at the surface of the sensor. Known concentrations of the olefin vapors were generated by bubbling $\mathrm{N}_{2}$ gas through a flask containing the liquid solvent and then into a dilution-air stream. For gaseous olefins a syringe pump was used to introduce the pure material into the air stream. The contaminant stream was divided between the sensor exposure chamber and an infrared gas analyzer (MIRAN 1A, Foxboro, Bridgewood, CT) used for continu- 
ous monitoring of solvent vapor concentrations. Dilution-air flow and temperature were controlled with a Miller-Nelson Research HCS 301 control unit. The relative humidity was maintained at $5 \pm 3 \%$ for all experiments.

\section{RESULTS AND DISCUSSION}

\section{Free-olefin substituent effects}

Our current and previous [10-13] tests of the SAW sensor coated with $\mathrm{PtCl}_{2}$ (ethylene)(pyridine) have revealed two general features of the sensor responses to olefin gases and vapors: they vary non-linearly with the olefin concentration and they exhibit a positive Arrhenius temperature dependence. Responses to styrene, ethyl acrylate and vinyl acetate as a function of concentration and temperature are shown in Fig. 1A and $B$, respectively. These data are representative of the those obtained with other reactive olefins. Each point on the curves represents the average rate of frequency change obtained at a given concentration over a period of 10-30 min. Responses are generally quite constant at a given concentration for such exposures. However, prolonged exposure leads to an eventual decline in response as the reagent becomes depleted. This occurs more rapidly at higher concentrations. With careful deposition technique, intercoating response variations can be maintained below $10 \%$.

The downward concavity in the responise curves is a consequence of the heterogeneous reaction between the gaseous olefin and the solid reagent which is the rate-limiting step in the overall analyte-coating interaction. $\log -\log$ plots of the sensor response versus concentration yield straight lines in accordance with a pseudo-first-order (with respect to the olefin) power-law kinetic model for the reactions [19]. For certain olefins, diffusional resistance within the reagent may also play a role in the overall interaction [13]. As mentioned above, regeneration of the $\mathrm{PtCl}_{2}$ (ethylene)(pyridine) is possible following exposure to the olefins
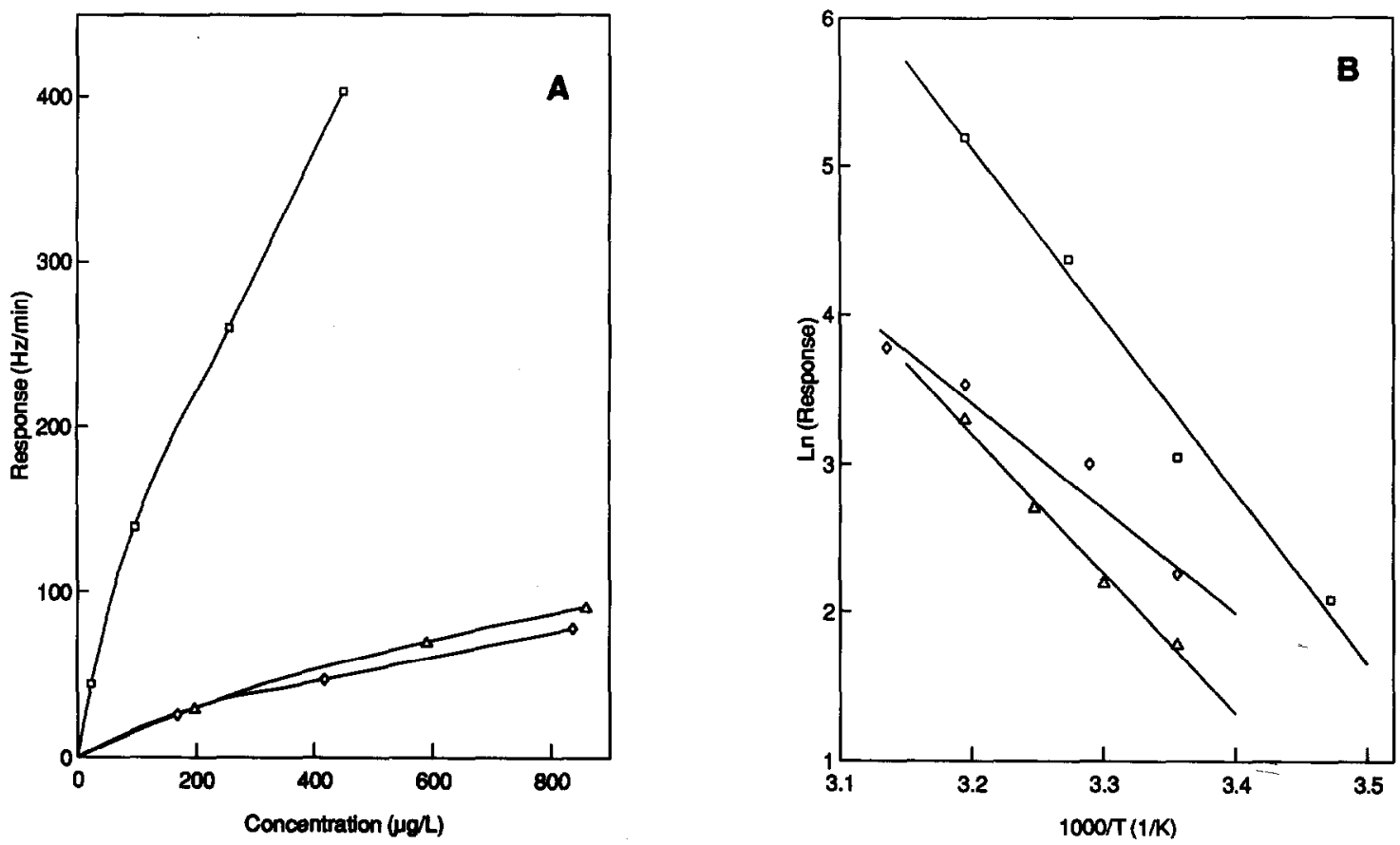

Fig. 1. Response of the $\mathrm{PtCl}_{2}$ (ethylene)(pyridine)-coated SAW sensor to $(\square)$ styrene $(\Delta)$ ethyl acrylate and $(\diamond)$ vinyl acetate as a function of (A) concentration at $40^{\circ} \mathrm{C}$; and (B) temperature at a fixed air concentration for each olefin. Each point represents the average response for a $10-30 \mathrm{~min}$ exposure. 
shown in Fig. 1 and for several other olefins. However, this issue is not examined in this paper.

The Arrhenius plots in Fig. 1B show that the slopes of the lines for styrene and ethyl acrylate are quite similar, indicating a similar activation energy for reaction. The slope for vinyl acetate is significantly smaller. This suggests a possible scheme for enhancing selectivity between certain olefins by the use of a simple sensor array where all the sensors are coated with the same reagent: the ratios of responses of two or three sensors operating at different temperatures should allow discrimination on the basis of activation energies.

In Table 2, responses from the sensor coated with $\mathbf{P t C l}_{2}$ (ethylene)(pyridine) are summarized for exposure to each of several different olefins. The limit of detection (LOD) is defined as the concentration corresponding to $3 \mathrm{~s} /$ sensitivity, where $s=1 \mathrm{~Hz}$ is the typical standard deviation of the 1-min frequency shifts measured before and after exposure. The sensitivity, in $\mathrm{Hz} /(\mu \mathrm{g}$ $\left.1^{-1}\right) \min ^{-1}$, is based on the slope of the response curve at the lowest measured concentration for each olefin. The rate of reaction shown in Table 2 was determined from Eqn. 3 assuming a nominal free-olefin concentration of $1 \mu \mathrm{g}^{-1}$. This latter measure accounts for the differences in mass change accompanying ethylene substitution.

An obvious trend in reactivity is observed between the groups listed in Table 2: olefins with strongly electron-withdrawing groups attached to the double bond (e.g., vinyl chloride, vinyl bromide, vinylidene chloride, trichloroethylene, acrylonitrile) do not react while those with moderately electron-withdrawing substituents (e.g., ethyl acrylate, methyl acrylate and vinyl acetate) or electron-donating substituents (e.g., aromatic olefins and alkenes) generally react quite readily. This inherent selectivity allows measurement of the reactive olefins in the presence of the non-reactive olefins even where the latter are present in large excess [11-13].

Within a given class of olefins, both steric and electronic factors appear to govern the relative reactivities. In the absence of such effects, sensitivity would be proportional to the difference in

TABLE 2

Limit of detection, sensitivity and molar reaction rate for various free olefins with trans- $\mathrm{PtCl}_{2}$ (ethylene)(pyridine) coatings at $40^{\circ} \mathrm{C}$

\begin{tabular}{|c|c|c|c|c|}
\hline $\begin{array}{l}\text { Free } \\
\text { olefin }\end{array}$ & $\begin{array}{l}\Delta \mathrm{MW}^{\mathrm{a}} \\
\left(\mathrm{g} \mathrm{mol}^{-1}\right)\end{array}$ & $\begin{array}{l}\text { LOD } \\
\left(\mu \mathrm{g} \mathrm{I}^{-1}\right)\end{array}$ & $\begin{array}{l}\text { Sensitivity } \\
{\left[\mathrm{Hz} /\left(\mu \mathrm{g} \mathrm{l}^{-1}\right) \mathrm{min}^{-1}\right]}\end{array}$ & $\begin{array}{l}\text { Reaction rate } \\
\left(\text { pmol } \text { min }^{-1}\right)\end{array}$ \\
\hline 4-Chlorostyrene & 110.6 & 0.38 & -8.0 & 95 \\
\hline 4-Methylstyrene & 90.1 & 0.65 & -4.7 & 68 \\
\hline Styrene & 76.1 & 1.4 & -2.1 & 37 \\
\hline$\beta$-Methylstyrene & 90.1 & 4.1 & -0.7 & 11 \\
\hline 1-Butene & 28.1 & 15 & -0.21 & 9.7 \\
\hline cis-2-Butene & 28.1 & 20 & -0.15 & 7.2 \\
\hline trans-2-Butene & 28.1 & 45 & -0.07 & 3.1 \\
\hline Isobutylene & 28.1 & $\mathrm{ND}^{\mathrm{c}}$ & - & - \\
\hline 1-Hexene & 56.1 & 1.0 & -2.9 & 68 \\
\hline Cyclohexene & 54.1 & 106 & -0.03 & 0.7 \\
\hline Vinyl acetate & 58.0 & 16 & -0.19 & 4.3 \\
\hline Ethyl acrylate & 72.1 & 22 & -0.14 & 2.5 \\
\hline Methyl acrylate & 58.0 & 62 & -0.05 & 1.1 \\
\hline Vinyl chloride & 34.5 & ND & - & - \\
\hline Vinyl bromide & 78.9 & ND & - & - \\
\hline Vinylidene chloride & 68.9 & ND & - & - \\
\hline Trichloroethylene & 103.3 & ND & - & - \\
\hline Acrylonitrile & 25.0 & ND & - & - \\
\hline
\end{tabular}

${ }^{a}$ Difference in molecular weight between free olefin and ethylene. ${ }^{b}$ Calculated at a nominal free-olefin concentration of $1 \mu \mathrm{g}$ $1^{-1}$. Not detected. 
MW between each olefin and ethylene. This is clearly not the case. Within the aromatic olefin group, the lower response for $\beta$-methylstyrene compared to styrene and the isomeric 4-methylstyrene can be attributed to the steric hindrance associated with the methyl group on the pendant double bond. The lower response for indene, however, is less easily explained. One would expect indene to give a higher response since the substituents on the coordinating double-bond are in a cis configuration. The anomolously low indene reactivity is apparently due to its fused ring structure. Upon coordination, the double bonded carbons in most olefins acquire some $\mathrm{sp}^{3}$ character with a commensurate change occuring in the bond lengths and bond angles in the molecule. In addition, the substituents on coordinated olefins are bent back away from the Pt atom to minimize repulsive non-bonded interactions with the $\mathrm{Pt}$ or the other ligands [9]. The inflexibility of the indene ring would inhibit such structural adjustments and destabilize the transition state for the reaction.

The increase in sensitivity observed in the series styrene, 4-methylstyrene and 4-chlorostyrene is much greater than expected from the MW differences alone, and can be attributed to the electronic influence of the 4-substituent (see Fig. 2). Interestingly, the addition of either an electron withdrawing or donating group enhances the reaction rate relative to styrene. These results are consistent with those reported for the relative thermodynamic stabilities of 4-substituted-styrene complexes of $\mathrm{Pt}(\mathrm{II})$ in solution [20]. But they are in contrast to that expected from ${ }^{13} \mathrm{C}$ NMR data reported on a series of styrene complexes where it was found that the coupling constants between $\mathrm{Pt}$ and the olefinic carbons increased with the electron-donating strength of the 4-substituent of styrene [21,22]. It is known, however, that the coupling constant is insensitive to the strength of the $\pi$ back-bonding in these complexes [21].

With respect to the alkenes and cycloalkenes in Table 2 , the trend in reactivity among the butene isomers (i.e., 1-butene $>$ cis-2-butene $>$ trans-2-butene $>$ isobutylene) can be ascribed to steric factors. The high reactivity of 1-hexene and low reactivity of cyclohexene were both unex-

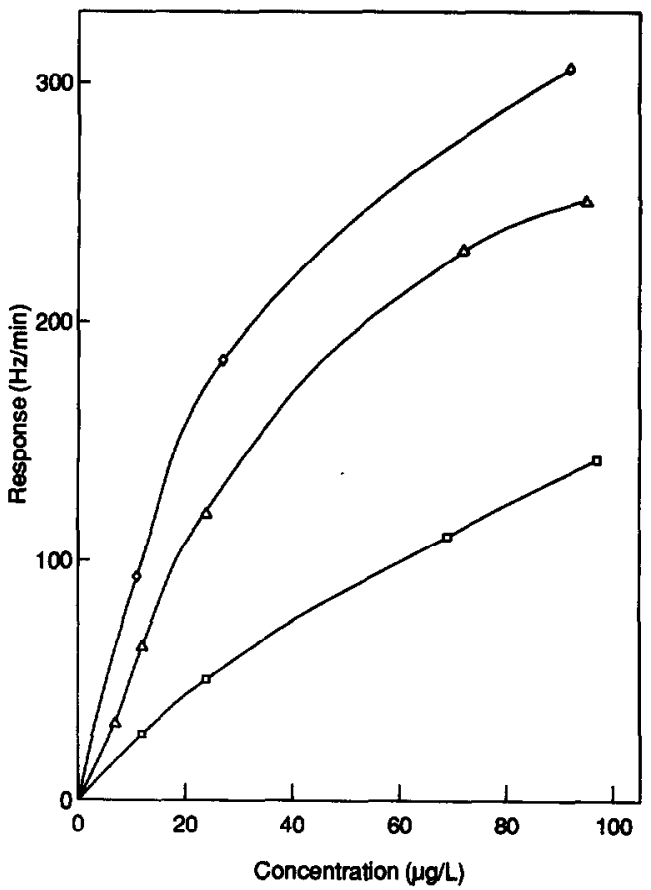

Fig. 2. Response of the $\mathrm{PtCl}_{2}$ (ethylene)(pyridine)-coated SAW sensor to $(\diamond)$ 4-chlorostyrene, $(\Delta)$ 4-methylstyrene and $(\square)$ styrene at $40^{\circ} \mathrm{C}$. Each point represents the average response for a 10-min exposure.

pected. As shown below, use of the 1-hexene complex as the reagent coating leads to higher sensitivity for several olefins than its lower-homologue complexes. Cyclohexene adopts a so-called half-chair configuration where the methylene groups attached to the double bond are cis [23]. One would therefore expect the double bond to be relatively accessible for coordination, analogous to the case of cis-2-butene. Unlike indene, structural adjustments accompanying coordination to Pt would be relatively facile for the sixmembered cyclohexene ring. While the low cyclohexene response is not completely understood, in light of the relatively high reactivity of 1-hexene and the results for indene relative to the other aromatic olefins, a high degree of selectivity against cyclic olefins is apparent.

The reactivities of vinyl acetate and ethyl acrylate are similar (see Fig. 1). This follows from the similarity in the electron-withdrawing strength of the ethoxycarbonyl and acetoxy groups as re- 
flected in their Hammet $\sigma_{\mathrm{p}}$ and $\sigma_{\mathrm{m}}$ constants [23]. Surprisingly, methyl acrylate is less reactive than both vinyl acetate (an isomer of methyl acrylate) and ethyl acrylate at all concentrations. Since steric factors can be ruled out, apparently there is a subtle difference in the electronic influence of the methyl and ethyl esters in the acrylates on the olefin double bond. It has been shown previously that the response to vinyl acetate is not affected by equivalent concentrations of methyl acrylate upon coexposure [11]. Methyl acrylate, however, will interfere with the response due to ethyl acrylate [13]. Notably, methylmethacrylate does not react to any measurable extent due to the steric hindrance of the additional methyl group on the olefin carbon.

In the absence of significant steric effects, the reactivities of the various olefins can be considered in terms of their orbital energies. As stated above, the $\mathrm{Pt}$-olefin bond strength depends on the contribution of both $\sigma$-type and $\pi$-type bonding. Meester et al. [24] studied the bonding properties of a similar series of trans- $\mathrm{PtCl}_{2}$ (ethylene)(amine) complexes and determined approximate energy levels for the highest-occupied and lowest-unoccupied $\mathrm{Pt}$ orbitals in these complexes based on spectroscopic data. Figure 3 presents a comparison of these energies with those of the corresponding orbitals of several of the free olefins tested here (data for the remaining olefins were not available). The trend in relative energies of the occupied orbitals follows that of the observed reactivities, with the exception of vinyl chloride. That is, those olefins with closer occupied-orbital energy matches to $\mathrm{Pt}$ are generally more reactive. The relative energies of the unoccupied orbitals do not follow this trend. These data support the view that the $\sigma$-bonding interaction is relatively more important than the $\pi$ back-bonding interaction in determining the reaction kinetics of these complexes.

\section{$\mathrm{PtCl}_{2}$ (ethylene)(4-X-pyridine)}

Figure 4 shows the sensor response to ethyl acrylate using the coating reagents $\mathrm{PtCl}_{2}$ (ethylene)(4-X-pyridine), where $\mathrm{X}=\mathrm{N}\left(\mathrm{CH}_{3}\right)_{2}, \mathrm{CH}_{3}, \mathrm{H}$, $\mathrm{Cl}$, and $\mathrm{CN}$. Once again, each point represents the mean rate of frequency change measured over 10-30 min at a given concentration. Similar series of exposures were performed with vinyl acetate and styrene. Representative responses are shown in Fig. 5 for individual cxposures to 2000

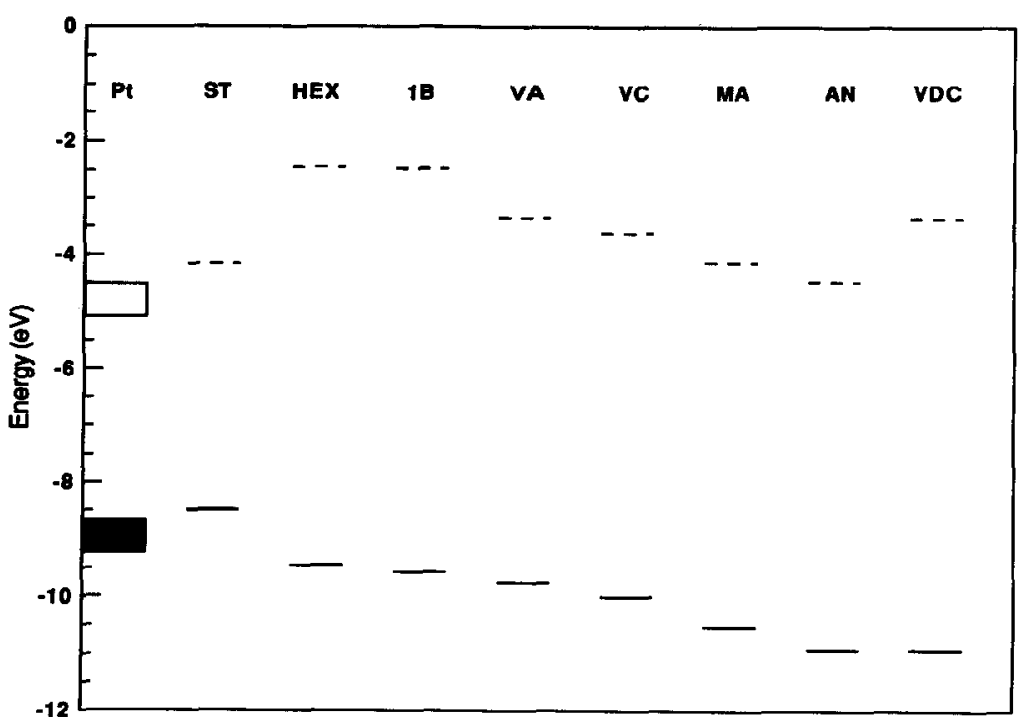

Fig. 3. Energy-level comparison of highest-occupied (- - ) and lowest unoccupied ( - - ) orbitals for several free olefins and $\mathrm{Pt}$ in $\mathrm{PtCl}_{2}$ (ethylene)(amine); $\mathrm{ST}=$ styrene, $\mathrm{HEX}=1$-hexene, $1 \mathrm{~B}=1$-butene, $\mathrm{VA}=$ vinyl acetate, $\mathrm{VC}=$ vinyl chloride, $\mathrm{MA}=$ methyl acrylate, $\mathrm{AN}=$ acrylonitrile and $\mathrm{VDC}=$ vinylidene chloride. 
$\mu \mathrm{g}^{-1}$ of ethyl acrylate and vinyl acetate at $30^{\circ} \mathrm{C}$ and $400 \mu \mathrm{g} \mathrm{l}^{-1}$ of styrene at $40^{\circ} \mathrm{C}$. The responses have been normalized separately for each of the olefins to the coating providing the highest response.

For styrene and vinyl acetate the pyridine complex gives the highest response, whereas for ethyl acrylate the highest response is observed with the 4-chloropyridine complex. The 4-hydroxypyridine and 4-(4-nitrobenzyl)pyridine complexes were also tested and found to give no reaction. Although these olefins could be identified based on the collective response patterns, the trends in the sensor responses shown in Fig. 5 are fairly similar, with a peak in reactivity occuring at an intermediate degree of amine basicity. The patterns for a given olefin will vary somewhat with concentration because the responses do not increase at exactly the same rate with concentration. However, the same order of responses is maintained over a wide range of con-

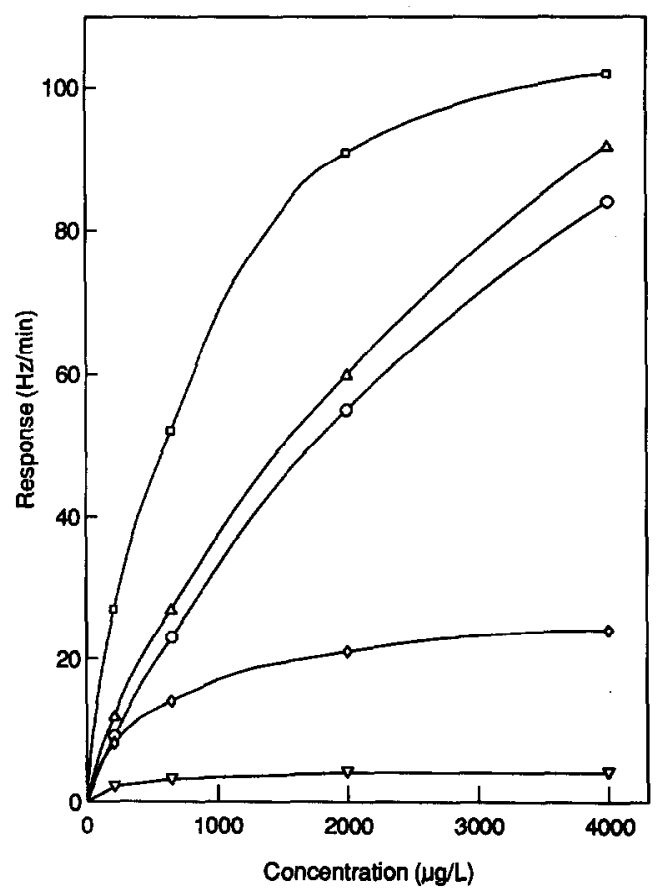

Fig. 4. Response to ethyl acrylate of the SAW sensor coated with $\mathrm{PtCl}_{2}$ (ethylene)(4-X-pyridine), where $\mathrm{X}=(\diamond) \mathrm{N}\left(\mathrm{CH}_{3}\right)_{2}$, (O) $\mathrm{CH}_{3},(\Delta) \mathrm{H},(\square) \mathrm{Cl},(\nabla) \mathrm{CN}$. Each point represents the average response for a $10-30 \mathrm{~min}$ exposure.

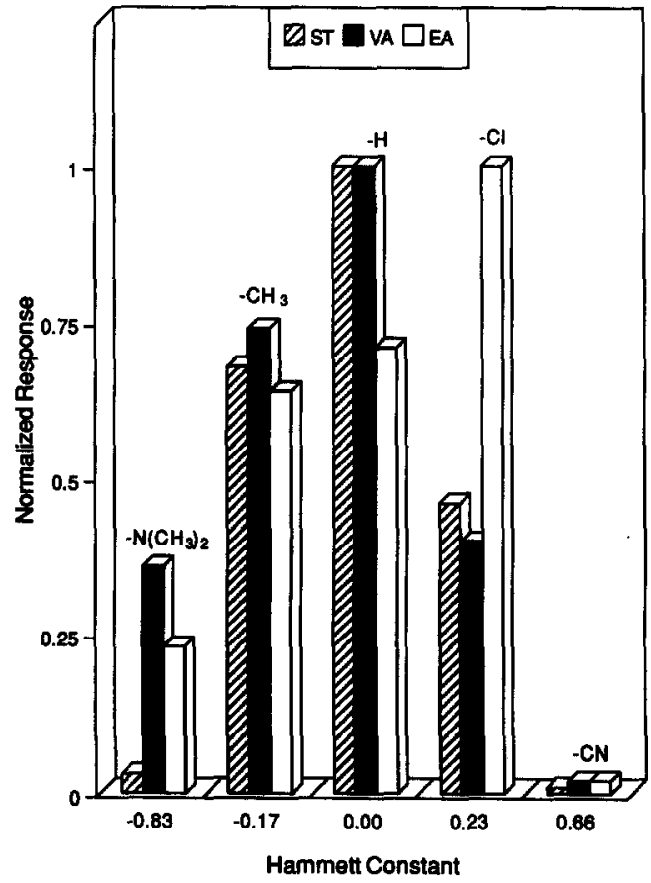

Fig. 5. Normalized responses to a given concentration of styrene (ST), vinyl acetate (VA) and ethyl acrylate (EA) as a function of the Hammett $\sigma_{\mathrm{p}}$ constant of $\mathrm{X}$ for the $\mathrm{PtCl}_{2}$ (ethylene)(4-X-pyridine)-coated sensor $\left[X=\mathrm{N}\left(\mathrm{CH}_{3}\right)_{2}, \mathrm{CH}_{3}, \mathrm{H}\right.$, $\mathrm{Cl}$, or $\mathrm{CN}]$.

centration. None of the 4-substituted pyridine complexes responded to vinyl chloride, vinyl bromide, vinylidene chloride or acrylonitrile.

The response patterns observed are different than what would have been expected based on solution-phase kinetic studies of similar complexes. The rates of olefin substitution in the complexes $\mathrm{PtCl}_{2}$ (2-methyl-2-butene)(4-X-pyridine) [16] and $\mathrm{PtCl}_{2}$ (styrene)(4-X-aniline) [17] increased markedly with the electron-withdrawing strength of $\mathrm{X}$. In the former case, the order of reactivity was $\mathrm{X}=\mathrm{CN}>\mathrm{Cl}>\mathrm{H}>\mathrm{CH}_{3}>\mathrm{NH}_{2}$ and a linear relationship was observed between the log of the rate constant and the Hammett $\sigma_{\mathrm{p}}$ constant of $X$. It has also been shown that the ${ }^{13} \mathrm{C}$ NMR chemical shifts of the olefinic carbons and the $\mathrm{Pt}-(\mathrm{C}=\mathrm{C})$ coupling constants also decrease in the same order, although the correlations are rather weak [22]. 
The reaction orders we observed are similar to the thermodynamic stabilities of olefin complexes in chloroform solution reported by Shupack and Orchin [25] where substitution of styrene by 1dodecene in a series of trans- $\mathrm{PtCl}_{2}$ (styrene)(4-Xpyridine $N$-oxide) showed a minimum value of the equilibrium constant for $X=H$ followed closely by the complex where $\mathrm{X}=\mathrm{Cl}$. Raman and IR data indicate that the strength of the Pt-ethylene bond in a series of $\mathrm{PtCl}_{2}$ (ethylene)(4-Xpyridine) complexes is not strongly affected by changes in the electron-withdrawing/donating strength of $X$ [26]. For the same series of complexes, however, the $\mathrm{Pt}-\mathrm{N}$ bond strength passes through a minimum at $X=H$ [27].

The influence of $\mathrm{X}$ observed here can be rationalized broadly in terms of the relative strengths of the $\sigma$ and $\pi$ bonding of the substituted pyridines. For pyridines with strongly electron donating groups, the $\mathrm{Pt}-\mathbf{N} \sigma$ bond is stronger and the Pt-ethylene $\pi$ bond is also stronger, leading to a stabilization of the ethylene complex toward substitution by the attacking olefins. For complexes having electron-withdrawing pyridine 4-substituents, apparently the Pt-N $\pi$ bond is strengthened and the Pt-ethylene $\sigma$ bond is also strengthened, again, leading to stabilization of the ethylene complex. Only at intermediate degrees of electron withdrawal/donation by the pyridine substituents is displacement of the ethylene favorable for these olefins.

\section{Particle size}

One potential mitigating factor affecting the observed sensor responses is the particle size distributions of the solid reagents when deposited on the sensor. The active surface area of the solid Pt-olefin complex could affect the reactivity. In order to investigate this factor, the size distributions of the reagents in the coating films were characterized. While the morphologies of the deposited solids varied from reagent to reagent, approximate values of the mean diameters and surface areas could be obtained using a projected area method and assuming spherical particles. Table 3 provides summary statistics of the particle size distributions measured for several coating films of each of the reagents tested. The values

\section{TABLE 3}

Geometric mean particle size and reagent surface area of deposited trans- $\mathrm{PtCl}_{2}$ (ethylene)(4-X-pyridine) coating reagents

\begin{tabular}{|c|c|c|c|}
\hline$\overline{\mathbf{X}}$ & $\begin{array}{l}\text { Geometric } \\
\text { mean } \\
\text { diameter } \\
(\mu \mathrm{m})\end{array}$ & $\begin{array}{l}\text { Coating } \\
\text { freqency } \\
\text { shift } \\
(\mathrm{kHz})\end{array}$ & $\begin{array}{l}\text { Reagent } \\
\text { surface } \\
\text { area }^{a} \\
\left(\mathrm{~mm}^{2}\right)\end{array}$ \\
\hline$-\mathrm{NH}_{3}$ & 1.10 & 272 & 11.2 \\
\hline$-\mathrm{OH}$ & 1.23 & 254 & 16.1 \\
\hline$-\mathrm{CH}_{3}$ & 1.23 & 274 & 13.1 \\
\hline$-\mathrm{H}^{\prime}$ & 1.17 & 247 & 16.5 \\
\hline$-\mathrm{Cl}$ & 1.00 & 269 & 14.9 \\
\hline$-\mathrm{CN}$ & 1.37 & 234 & 22.6 \\
\hline
\end{tabular}

Determined assuming approximately spherical particles within the coating.

for the pyridine complex are viewed with skepticism because the morphology of this reagent was particularly variable. The data shown in Table 3 were obtained using films deposited directly on the sensor that were subsequently exposed to one of the olefins.

While there is some variation in the mean particle diameters and calculated surface areas, the differences could not account for the observed differences in reactivity. The densities of the complexes may also be important, since the free olefin must diffuse into the reagent during reaction. This factor was not investigated, but is not likely to differ greatly between these complexes.

$$
\text { ide) }
$$

$\mathrm{PtCl}_{2}$ (ethylene)(4-X-aniline, 4-X-pyridine $\mathrm{N}$-ox-

Complexes having other trans-amine ligands were then deposited on the sensor and tested for their responses to ethyl acrylate at $30^{\circ} \mathrm{C}$. In all cases, ethylene was the initially complexed olefin. It had been determined previously that the complex having $\mathrm{NH}_{3}$ as the amine ligand showed no reactivity toward styrene, so this complex was not tested further with ethyl acrylate. Where the amine was 4-X-pyridine $N$-oxide, responses were in the order $\mathrm{X}=\mathrm{H}>\mathrm{CH}_{3}>\mathrm{Cl}$ and in all cases were significantly lower than those for the corresponding pyridine complexes. As mentioned above, the maximum response for $X=H$ is con- 
sistent with the trend in the thermodynamic stability of 4-X-pyridine $\mathrm{N}$-oxide complexes of styrene [25]. For the 4-X-aniline series, responses were in the order $\mathrm{CH}_{3}>\mathrm{H}>\mathrm{Cl}$ and were greater than those for the corresponding pyridine $N$ oxides but less than those for the pyridine series. Although thermodynamic data on the aniline complexes were not available, the kinetic study cited above [17] indicated a trend opposite to that observed here, i.e., substitution rates generally increased with the electron-withdrawing strength of $\mathrm{X}$. It was found for the aniline complexes, and to a lesser extent for the pyridine $\mathrm{N}$-oxide complexes, that the sensor responses decreased rapidly at a given ethyl acrylate concentration within a few minutes of exposure.

\section{$\mathrm{PtCl}_{2}$ (olefin) (pyridine)}

Attempts to prepare complexes where $\mathrm{OL}_{1}=$ vinyl chloride and trichloroethylene were unsuccessful. However, complexes of 1-butene, 1hexene and 1-octene, with pyridine as the transamine ligand, could be prepared easily and allowed a systematic examination of the effect of progressively longer alkyl side chains on the olefin substitutional lability. Results of exposure to three different free olefins are summarized in Fig. 6 and Table 4. For exposure to ethylene, there is a steady increase in response with increasing alkyl chain length and all frequency shifts are positive because of the loss of mass from the coatings. As shown in Table 4 the response ratios are 3:2:1 for the 1-octene, 1-hexene, and 1-butene complexes, respectivcly, in agreement with the ratios expected based on the mass differences alone. Thus, there does not appear to be any difference due to electronic factors. In contrast, with ethyl acrylate the response pattern is quite different. The ethylene and 1-butene complexes show about the same responses, which indicates that the latter reagent is reacting at a higher rate since the net mass change is smaller. The 1-octene complex gives a large response, indicating an even higher reaction rate because of the similarity in MW between ethyl acrylate and 1-octene. In contrast to ethylene and 1-butene complexes, the response using the 1-octene complex is positive because there is a net mass loss from the surface upon

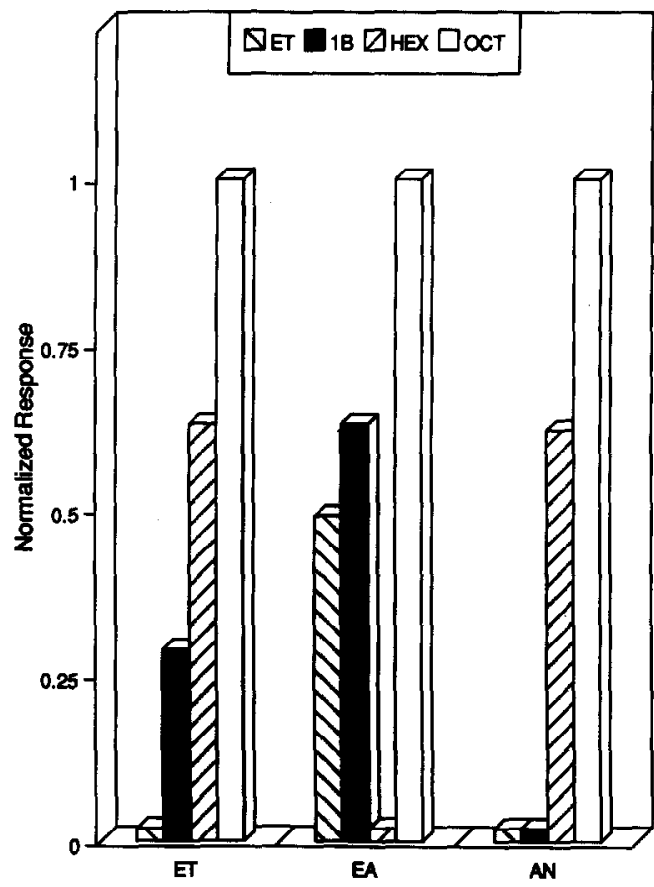

Fig. 6. Normalized responses to ethylene (ET), ethyl acrylate (EA) and acrylonitrile (AN) as a function of $\mathrm{OL}_{1}$ for the $\mathrm{PtCl}_{2}\left(\mathrm{OL}_{1}\right)$ (pyridine)-coated sensor where $\mathrm{OL}_{1}=$ ethylene, 1-butene (1B), 1-hexene (HEX) or 1-octene (OCT) (note: with the exception of EA reacting with the ethylene and 1-butene complexes, all responses are positive since there is a net loss of mass from the sensor coatings).

reaction with ethyl acrylate. Surprisingly, ethyl acrylate did not react to any measurable extent with the 1-hexene complex. The reason for this is not clear. When acrylonitrile is exposed to each of these coatings, no responses are observed for the ethylene or 1-butene complexes, but large responses in the ratio of about $2: 3$ are obtained using the 1-hexene and 1-octene complexes, respectively (positive responses are obtained for these coatings, again, because of the net loss of mass from the sensor surface). Vinyl chloride gives small concentration dependent responses with the 1-hexene and 1-octene complexes, but vinylidene chloride could not be detected with any of the sensor coatings investigated.

Additional tests involving exposure to the butene isomers were performed using the 1hexene complex coating. The LODs at $25^{\circ} \mathrm{C}$ are $1.6,1.7,5.3$, and $49 \mu \mathrm{g}^{-1}$ for 1-butene, cis-2- 


\section{TABLE 4}

Comparison of sensor responses to each of several free olefins using different trans- $\mathrm{PtCl}_{2}$ (olefin)(pyridine) coatings

\begin{tabular}{|c|c|c|c|c|}
\hline $\begin{array}{l}\text { Initially } \\
\text { complexed } \\
\text { olefin }\end{array}$ & $\begin{array}{l}\Delta \mathrm{MW} \\
(\mathrm{g} / \mathrm{mol})\end{array}$ & $\begin{array}{l}\Delta \mathrm{MW} \\
\text { ratio }\end{array}$ & $\begin{array}{l}\text { Sensitivity } \\
{\left[\mathrm{Hz} /\left(\mu \mathrm{g} \mathrm{l}^{-1}\right) \min ^{-1}\right]}\end{array}$ & $\begin{array}{l}\text { Sensitivity } \\
\text { ratio }\end{array}$ \\
\hline \multicolumn{5}{|c|}{ Free olefin $=$ ethylene } \\
\hline Ethylene & 0.0 & - & - & - \\
\hline 1-Butene & 28.0 & 1.0 & 0.64 & 1.0 \\
\hline 1-Hexene & 56.1 & 2.0 & 1.4 & 2.2 \\
\hline 1-Octene & 84.1 & 3.0 & 2.1 & 3.1 \\
\hline \multicolumn{5}{|c|}{ Free olefin $=$ ethyl acrylate } \\
\hline Ethylene & 72.1 & 6.0 & -0.031 & 0.5 \\
\hline 1-Butene & 44.0 & 3.6 & -0.040 & 0.6 \\
\hline 1-Hexene & 16.0 & 1.3 & ND & - \\
\hline 1-Octene & -12.1 & 1.0 & 0.064 & 1.0 \\
\hline \multicolumn{5}{|c|}{ Free olefin = acrylonitrile } \\
\hline Ethylene & 25.0 & 8.3 & ND & - \\
\hline 1-Butene & 3.0 & 1.0 & ND & - \\
\hline 1-Hexene & -31.1 & 10.3 & 0.21 & 1.0 \\
\hline 1-Octene & -59.1 & 19.7 & 0.34 & 1.6 \\
\hline
\end{tabular}

${ }^{a}$ Evaluated at $50 \mu \mathrm{g} 1^{-1}$ for ethylene $\left(30^{\circ} \mathrm{C}\right), 1000 \mu \mathrm{g} \mathrm{l}^{-1}$ for ethyl acrylate $\left(30^{\circ} \mathrm{C}\right)$ and $300 \mu \mathrm{g}^{-1}$ for acrylonitrile $\left(25^{\circ} \mathrm{C}\right)$. $\mathrm{ND}=$ Not detected.

butene, trans-2-butene and isobutylene, respectively. Comparison of these results with those in Table 2 shows that the 1-hexene complex is much more sensitive to these compounds than the ethylenc complex.

\section{Conclusions}

The results presented here demonstrate the ability to adjust the selectivity and sensitivity of SAW sensors toward various olefin gases and vapors through subtle changes in the electronic structural features of the reagent coatings. The inherent selectivity for relatively electron-rich olefins arises from the apparent predominance of $\sigma$-bonding interactions between the olefins and $\mathrm{Pt}$, though the trends observed in the data suggest that $\pi$ back-bonding is also important. The exceptional behavior observed in several exposure series, however, indicates that the dynamics of these reactions cannot be fully rationalized in terms of simple variations in $\sigma$ and $\pi$ bonding strength alone. Still, advantage can be taken of the observed selectivities. The remarkably high response to 1-hexene relative to 1-butene and cyclohexene using $\mathrm{PtCl}_{2}$ (ethylene)(pyridine) and the ability to measure electron-deficient olefins by extending the alkyl side chain of the initially complexed olefin are particularly noteworthy.

The patterns of response as a function of the amine ligands in these complexes differ from those expected from previous solution-phase kinetic studies and NMR data on these and similar complexes. In contrast, fairly consistent correlations are found with thermodynamic stability data for similar systems which suggests the possibility of quasi-equilibria being established at or just beneath the surface of the solid reagents even under dynamic exposure conditions.

In some practical situations, use of a single SAW sensor coated with one of the reagents studied here could provide sufficient selectivity in the presence of non-olefins or certain other (non-reactive) olefins. The use of a simple sensor array comprising as few as two sensors coated with the same reagent complex, but operated a different temperatures, could provide selectivity based on differences in activation energy between different reacting olefins. Finally, an array of sensors having different reagent coatings could provide discrimination between a wider range of olefins on the basis of differences in steady-state response.

This work was supported by Grant No. R01$\mathrm{OH} 02663$ from the National Institute for Occupational Safety and Health of the Centers for Disease Control.

\section{REFERENCES}

1 American Conference of Governmental Industrial Hygienists (ACGIH), Documentation of the Threshold Limit Values and Biological Exposure Indices, ACGIH, Cincinnati, $\mathrm{OH}, 1985$.

2 Code of Federal Regulations, 29CFR1910.1000, January 19, 1989, U.S. Department of Labor, Occupational Safety and Health Administration, Occupational Safety and Health Standards.

3 American Conference of Governmental Industrial Hygienists (ACGIH), 1992-1993 Threshold Limit Values and Biological Exposure Indices, ACGIH, Cincinnati, OH, 1992. 
4 J.S. Nader, J.F. Lauderdale and S.C. McCammon, in S.V. Hering (Ed.), Air Sampling Instruments for Evaluation of Atmospheric Contaminants, American Conference of Governmental Industrial Hygienists, Cincinnati, $\mathrm{OH}$, 7th edn., 1989, pp. 507-582.

5 M.S. Nieuwenhuisen and A. Venema, Sens. Mater., 5 (1989) 261.

6 H. Wohltjen, D.S. Ballantine, Jr. and N.L. Jarvis, in R.W. Murray (Ed.), Chemical Sensors and Microinstrumentation, ACS Symposium Series 403, American Chemical Society, Washington, DC, 1989, pp. 157-175.

7 H. Wohltjen, Sensors Actuators, 5 (1984) 307.

8 M. Herberhold, Metal $\pi$-Complexes, Vol. 1, Parts 1, 2, Elsevier, Amsterdam, 1974.

9 F.R. Hartley, in G. Wilkinson (Ed.), Comprehensive Organometallic Chemistry - The Synthesis, Reaction and Structures of Organometallic Compounds, Vol. 6, Pergamon, Oxford, 1982, pp. 614-754.

10 E.T. Zellers, R.M. White and S.M. Rappaport, Anal. Chem., 62 (1990) 1223.

11 E.T. Zellers, in R.W. Murray (Ed.), Chemical Sensors and Microinstrumentation, ACS Symposium Series 403, American Chemical Society, Washington, DC, 1989, pp. 176190.

12 E.T. Zellers, N.C. Hassold, R.M. White and S.M. Rappaport, Anal. Chem. 62 (1990) 1227.

13 E.T. Zellers and G.Z. Zhang, Anal. Chem., 64 (1992) 1277.
14 M. Orchin and P.J. Schmidt, Inorg. Chim. Acta. Rev., (1968) 123.

15 F.R. Hartley, Chem. Rev., 73 (1973) 163.

16 S. Miya, K. Kashiwabara and K. Saito, Inorg. Chem., 19 (1980) 98.

17 S.S. Hupp and G. Dahlgren, Inorg. Chem., 15 (1967) 2349.

18 D.G. Taylor (Ed.), NIOSH Manual of Analytical Methods, Vol. 1, USDHEW-NIOSH, Cincinnati, $\mathrm{OH}$, 2nd edn., 1977, pp. 239(1)-239(21).

19 L.K. Doraiswamy and M.M. Sharma, Heterogeneous Reactions: Analysis, Examples, and Reactor Design, Vol. 1, Wiley, New York, 1984, Chap. 2.

20 J. Joy and M. Orchin, J. Am. Chem Soc., 81 (1959) 305.

21 D.G. Cooper and J. Powell, Inorg. Chem., 15 (1976) 1959.

22 D.G. Cooper and J. Powell, Inorg. Chem., 16 (1977) 142.

23 F.A. Carey and R.J. Sundberg, Advanced Organic Chemistry - Part A: Structure and Mechanisms, Plenum, New York, 2nd edn., 1984.

24 M.A.M. Meester, H. vanDam, D.J. Stufkens and A. Oskam, Inorg. Chim. Acta, 20 (1976) 155.

25 S.I. Shupack and M. Orchin, J. Am. Chem. Soc., 86 (1964) 586.

26 M.A.M. Meester, D.J. Stufkens and K. Vriese, Inorg. Chim. Acta, 14 (1975) 25.

27 M.A.M. Meester, D.J. Stufkens and K. Vriese, Inorg. Chim. Acta, 21 (1977) 251. 